\title{
Cystic fibrosis screening: Lessons learned from the first 320,000 patients
}

Charles M. Strom, MD, PhD, Beryl Crossley, MD, Joy B. Redman, MS, Arlene Buller, PhD, Franklin Quan, PhD, Mei Peng, PhD, Matthew McGinnis, PhD, and Weimin Sun, PhD

\begin{abstract}
Purpose: To examine the data from $>335,000$ Cystic fibrosis (CF) tests to detect unsuspected findings and obtain clinical data when indicated to optimize genetic counseling. Methods: A proprietary database containing 335,204 consecutive CF DNA tests and 445 CF prenatal diagnostic tests was queried. Clinical information was obtained for prenatal and selected nonprenatal cases by telephone contact with physician offices. Results: The mutation 1078delT was found in much lower frequency than expected with rates of only 1:55,867 tests and $0.06 \%$ of $\mathrm{CF}$ mutations. This level is below the threshold set by the American College of Medical Genetics. Homozygosity was observed for 2789+5G>A in a 29-year-old women and compound heterozygosity with delta F408 in a 40 -year-old woman with isolated chronic sinusitis. Many patients elected prenatal diagnosis when not at a 1:4 risk due to echogenic bowel or IVS-8 5T issues. Conclusions: With the exception of 1078delT, all CF mutations in the ACMG panel were detected with a frequency of $>0.1 \%$ of CF chromosomes. When ACMG guidelines are strictly adhered to, population-based CF carrier screening will accurately identify couples at risk for having children with CF. Genet
\end{abstract} Med 2004:6(3):136-140.

Key Words: cystic fibrosis, ACMG guidelines, carrier screening

Cystic Fibrosis (CF) is the most common genetic disease affecting Caucasians with an incidence of approximately $1: 3,300$ to $1: 3,360$ births $^{1,2}$ Classical CF is a multisystem disease caused by the plugging of alveoli and pancreatic ducts with viscous mucus resulting in exocrine pancreatic insufficiency, pancreatitis, chronic lung disease, recurrent pneumonitis, and congenital bilateral absence of the vas deferens (CBAVD) in males. ${ }^{3,4}$ The CF foundation estimates that there are approximately 30,000 individuals with CF currently living in the United States. ${ }^{5}$

Although most prevalent in Caucasians, CF is seen in all ethnic groups in the US with frequencies of 1:8,000-9,500, 1:15,300, and 1:32,100 in Hispanics, African Americans, and Asian Americans, respectively. ${ }^{1}$ Carrier frequencies in the US, estimated from incidence figures, are 1:31 for the US population as a whole, 1:28 for Caucasians, ${ }^{6}$ 1:46 for Hispanics, 1:60-65 for African Americans, and 1:90 for Asian Americans. $^{2}$

The gene responsible for $\mathrm{CF}$, the $\mathrm{CF}$ transmembrane regulator protein (CFTR), was identified in 1988. ${ }^{7-9}$ More than 1000 different mutations in CFTR have been described in CF patients. These are compiled in an electronic database maintained by Toronto Sick Children's Hospital. ${ }^{10}$ The presence of

Nichols Institute, Quest Diagnostics, San Juan Capistrano, California.

Charles M. Strom, Medical Director, Genetics, Nichols Institute, Quest Diagnostics, 33608 Ortega Highway, San Juan Capistrano, CA 92690.

Received: September 9, 2003.

Accepted: January 27, 2004.

DOI: 10.1097/01.GIM.0000127268.65149.69 a mutation in a CF patient and hence in the database provides presumptive but not conclusive evidence that the particular mutation is capable of causing CF. In May 2001, the American College of Medical Genetics (ACMG) published a recommended panel of 25 mutations and 6 polymorphisms for US population based carrier screening. ${ }^{2}$ These particular mutations were chosen because they had $>0.1 \%$ frequency in CF patients. The ACMG also recommended that a reflex test for the IVS-8 5T variant be performed in the presence of the mild CF mutation $\mathrm{R} 117 \mathrm{H}^{2}$

As with the introduction of any large scale screening program, the initial 18 months of population-based CF carrier screening revealed the imperfections of such a program. The initial ACMG recommended panel used the Toronto Sick Children's Database ${ }^{10}$ among others, as a reference for CF mutations and their frequencies. Further work by another laboratory established that in CF patients, the I148T caused CF almost exclusively when coupled with a second, much rarer mutation, 3199del6. ${ }^{11-13}$ This haplotype also includes the IVS-8 9T allele. In response to these new data, the ACMG published an advisory recommending that any patient who is discovered to have I148T and 9T should be tested for 3199del6. If the patient is negative for 3199 del6, they can be counseled that their risk of being a CF carrier is low. ${ }^{11}$

It is possible that invasive prenatal procedures were performed on women not truly at risk for having a fetus with CF. Based on this new information it is possible an unaffected fetus might have been terminated based on a genotype of I148T and another CF mutation. The current policy in our laboratory if we receive a prenatal sample, and the primary indication for 
testing is that one or both parents carries I148T, is to contact the physician and advise him or her. Other laboratories may have differing practices. It is important to note the other 24 mutations on the original ACMG panel are not found in higher than predicted frequencies, reinforcing the conclusion that they are, in fact, true CF mutations.

Clinical interpretations must be continuously reevaluated in light of new data. This article reports our experience performing 335,204 carrier tests and 445 prenatal diagnoses using the ACMG/American College of Obstetricians and Gynecologists (ACOG) panel and some of the lessons learned from this experience. We believe such empirical data are essential in the on-going evaluation of $\mathrm{CF}$ carrier testing.

\section{MATERIALS AND METHODS}

From July 2001 until December 2002, assays were performed using the CF Gold Line Probe assay strips (Roche Molecular Systems) as described previously. ${ }^{12}$ Subsequently in December 2002, we began using the CF OLA ASR reagent (Applied Biosystems) run on an ABI 3100 automated DNA sequencer. In the line probe assay, results were entered manually into a proprietary database, which included the presence or absence of the IVS-8 5 T allele (5T). Data were automatically uploaded using the OLA assay and the actual IVS-8 genotype was stored (i.e., 7T/9T). Race was not captured into this database. Attempts were made to contact physician offices to obtain clinical information for all patients found to be have two CF mutations that were not sent from known CF centers. Clinical information for selected patients was obtained by telephone contact with the referring physicians' offices.

\section{RESULTS AND DISCUSSION}

Table 1 shows the genotype frequency of the initial 335,204 consecutive patients tested in our laboratory using the ACMG recommended panel. Because current evidence suggests that I148T is not CF causing mutation (see earlier) the 1,136 patients with I148T have been considered "wild type" and excluded from the table. In addition, patients with R117H are divided into those with and those without the $5 \mathrm{~T}$ variant because only those individuals with $\mathrm{R} 117 \mathrm{H}$ and $5 \mathrm{~T}$ in the same allele are at risk for having children with classic CF. It is assumed that the overwhelming majority of patients were tested based on the ACOG recommendations for population based screening but the data could not be sorted by indication for testing. Although our database does not specify race, experience suggests that individuals of all ethnic groups are being screened, and not just Ashkenazi Jews and Caucasians. The initial recommendations were to recommend screening to Caucasian and Ashkenazi Jewish couples but to inform couples of other ethnic or racial groups that CF screening is available.

We queried our database to learn whether the expected incidence of CF carriers detected in our population matches the incidence of 1:29 predicted from the frequency of CF of 1:3,300 in US Caucasians. ${ }^{1}$ Because the ACMG panel is only expected
Table 1

Frequency of CF mutations found in 335,204 consecutive patients ${ }^{a}$

\begin{tabular}{|c|c|c|c|}
\hline Mutation & $\begin{array}{c}\text { Total } \\
\text { no. }\end{array}$ & $\begin{array}{l}\text { Frequency, } \\
\text { all tests }\end{array}$ & $\begin{array}{c}\text { Frequency, } \\
\text { CF mutations } \\
(\%)\end{array}$ \\
\hline delta F508 & 7610 & $1: 44$ & $75 \%$ \\
\hline $\mathrm{R} 117 \mathrm{H} / 7 \mathrm{~T}$ or $9 \mathrm{~T}$ & 1030 & $1: 325$ & $\mathrm{NA}^{b}$ \\
\hline $\mathrm{R} 117 \mathrm{H} / 5 \mathrm{~T}$ & 103 & $1: 3,254$ & $0.51^{c}$ \\
\hline W1282X & 529 & $1: 625$ & 5.2 \\
\hline G542X & 382 & 1:909 & 3.8 \\
\hline G551D & 278 & $1: 1,250$ & 2.7 \\
\hline N1303K & 201 & $1: 1,668$ & 2.0 \\
\hline $3849+10 \mathrm{~kb} C>\mathrm{T}$ & 167 & $1: 2,007$ & 1.6 \\
\hline $1717-1 \mathrm{G}>\mathrm{A}$ & 102 & $1: 3,286$ & 1.0 \\
\hline R553X & 102 & $1: 3,286$ & 1.0 \\
\hline $621+1 \mathrm{G}>\mathrm{T}$ & 98 & $1: 3,420$ & 0.97 \\
\hline $2789+5 \mathrm{G}>\mathrm{A}$ & 82 & $1: 4,087$ & 0.80 \\
\hline $3120+1 \mathrm{G}>\mathrm{A}$ & 73 & $1: 4,591$ & 0.72 \\
\hline R1162X & 54 & $1: 6,207$ & 0.53 \\
\hline R334W & 54 & $1: 6,207$ & 0.53 \\
\hline $685 \mathrm{E}$ & 52 & $1: 6,446$ & 0.51 \\
\hline $\mathrm{R} 560 \mathrm{~T}$ & 52 & $1: 6,446$ & 0.51 \\
\hline Delta I507 & 51 & $1: 6,572$ & 0.50 \\
\hline $711+1 \mathrm{G}>\mathrm{T}$ & 40 & $1: 8,380$ & 0.39 \\
\hline $1898+1 \mathrm{G}>\mathrm{A}$ & 37 & $1: 9,059$ & 0.36 \\
\hline 3659 del C & 36 & $1: 9,311$ & 0.36 \\
\hline $\mathrm{A} 455 \mathrm{E}$ & 34 & $1: 9,858$ & 0.33 \\
\hline R347P & 33 & $1: 10,158$ & 0.32 \\
\hline $2184 \mathrm{del} A$ & 14 & $1: 23,943$ & 0.14 \\
\hline $1078 \mathrm{del} \mathrm{T}$ & 6 & $1: 55,867$ & 0.06 \\
\hline
\end{tabular}

${ }^{a} \mathrm{I} 148 \mathrm{~T}$ has been eliminated from these data.

${ }^{b} \mathrm{R} 117 \mathrm{H}$ without 5T is not considered a classic CF mutation (see text). ${ }^{c}$ Only half of these patients were used for calculations due to the prediction that $50 \%$ of the $5 \mathrm{~T}$ alleles will be in trans to the $\mathrm{R} 117 \mathrm{H}$ (see text).

to detect $88.34 \%$ of CF chromosomes in non-Hispanic US Caucasians, ${ }^{6}$ we would expect to identify approximately $1: 32$ individuals to be CF carriers using the ACMG panel. Using the data from Table 1, which omits I148T cases, excludes carriers of the mild mutation $\mathrm{R} 117 \mathrm{H}$ without $5 \mathrm{~T}$, and also excludes half of the patients with R117H and 5T (because only half would be predicted to have the $5 \mathrm{~T}$ in cis), there are 10,139 carriers of classic CF. This yields a carrier frequency of $1: 33$ that is similar to the prediction of 1:32.

One mutation, 1078delT, is observed much less frequently than initially predicted, with a population frequency of $1: 55,867$, accounting for $0.06 \%$ of detected CF mutations. Had the ACMG applied the $0.1 \%$ incidence threshold (see earlier discussion) to these data, 1078delT would not have been chosen for the panel. It is possible that the assays used in our 
laboratory did not detect all patients with this mutation. Genomic controls consistently performed well on both platforms, and both platforms yielded similar frequencies, with 5 individuals detected in 233,955 Roche tests and 7 individuals detected in 238,975 ABI tests yielding frequencies of 0.0000213 and 0.0000292 , respectively. These numbers are in excess of the 335,204 described in Table 1 due to fact that this query was made at a later date than the queries performed for the original manuscript preparation. These facts argue that the assay is, in fact, performing well.

We detected 1,136 patients with I148T in this series. After the publication of the association of the haplotype I148T/ IVS-8 9T/3199del6 with CF, ${ }^{13}$ we began analyzing the IVS-8 status for all patients found to have I148T. Of 544 heterozygous patients for I148T, only $86(16 \%)$ lacked the 9T allele. Because most patients with I148T will have the 9T allele and the number of patients in the initial published study ${ }^{13}$ was only 9 , we believe that all patients found to have I148T should be offered 3199del6 testing regardless of their IVS-8 genotype. Approximately $1 \%$ of more than 400 patients with I148T were found to have 3199del6 (data submitted elsewhere). In our series of 335,204 tests, 1,136 patients had I148T, predicting that approximately 11 patients would be expected to have 3199del6. In comparison with the mutations on the ACMG panel, 3199del6 would be the second least frequent CF allele with an incidence of $0.1 \%$ of CF mutations.

Table 2 is a summary of individuals found to have $2 \mathrm{CF}$ mutations. These are all postnatal samples and no efforts to determine the phase of $5 \mathrm{~T}$ and $\mathrm{R} 117 \mathrm{H}$ were made. Clinical information was sought only when there was an apparent discrepancy between the genotype and the clinical situation; for example, when $2 \mathrm{CF}$ mutations were found in a female sample referred by an Obstetrician's office. One sample obtained from a CF center had the genotype delta F508/R117H without 5T. This 4-year-old female patient had chronic asthma, a positive sweat test, and the presumptive diagnosis of CF. There was also a male patient homozygous for $\mathrm{R} 117 \mathrm{H}$ without $5 \mathrm{~T}$ who was azoospermic and infertile but had bilateral presence of vas deferens.

Table 3 summarizes clinical data for 4 women who were referred for general population obstetrical screening who were

Table 2

Individuals in whom $2 \mathrm{CF}$ mutations were detected

\begin{tabular}{llc}
\hline Mutation 1 & \multicolumn{1}{c}{ Mutation 2 } & No. of patients \\
\hline$\Delta$ F508 & $\Delta$ F508 & 116 \\
$\Delta$ F508 & Classic CF mutation ${ }^{a}$ & 55 \\
$\Delta$ F508 & R117H & 38 \\
R117H & R117H & 4 \\
R117H & Classic CF mutation & 6 \\
Classic CF mutation & Classic CF mutation & 20 \\
\hline
\end{tabular}

${ }^{a}$ All ACMG panel mutations except R117H (without 5T) and $\Delta$ F508. R117H in cis to $5 \mathrm{~T}$ is considered a classic CF mutation.
Table 3

Patients with 2 CF mutations and unexpected phenotypes

\begin{tabular}{|c|c|c|c|}
\hline Genotype & Gender & Age & Symptoms \\
\hline$\Delta$ F508/R117H & Female & 22 years & no respiratory symptoms \\
\hline$(5 \mathrm{~T} / 9 \mathrm{~T})$ & & & 3 episodes of pancreatitis \\
\hline $\begin{array}{l}\Delta \mathrm{F} 508 / 3849 \\
\quad+10 \mathrm{~kb} \\
\quad \mathrm{C}>\mathrm{T}\end{array}$ & Female & Adult & chronic pancreatitis \\
\hline $\begin{array}{l}2789+5 \\
\quad \mathrm{G}>\mathrm{A} / 2789+5 \\
\mathrm{G}>\mathrm{A}^{a}\end{array}$ & Female & 29 years & chronic sinusitis \\
\hline $\begin{array}{l}\Delta \mathrm{F} 508 / 2789+5 \\
\quad \mathrm{G}>\mathrm{A}\end{array}$ & Female & 40 years & $\begin{array}{l}\text { recurrent sinusitits } \\
\text { requiring surgery }\end{array}$ \\
\hline
\end{tabular}

${ }^{a}$ Both parents confirmed to be carriers of $2789+5 \mathrm{G}>\mathrm{A}$.

found to have 2 CF mutations. Two of these patients have isolated pancreatitis without significant pulmonary disease and have the genotype delta F508/R117H (with an IVS-8 genotype of 9T/5T) and delta F508/2849+10kb C $\rightarrow$ T respectively. The other two have chronic sinusitis alone without lower respiratory tract disease or pancreatitis. One individual was homozygous for $2789+5 \mathrm{G}>\mathrm{A}$ and the other was compound heterozygous for $2789+5 \mathrm{G}>\mathrm{A}$ and delta F508 (see Table 3). It is possible that the $2789+5 \mathrm{G}>\mathrm{A}$ mutation is a mild CF mutation, causing sinusitis comparable to $\mathrm{R} 117 \mathrm{H}$ causing CBAVD. The $2879+5 \mathrm{G} \rightarrow \mathrm{A}$ mutation has been previously described as being associated with milder disease. ${ }^{14}$ Other published data sets regarding CF genotype/phenotype correlations suffer from ascertainment bias, as only symptomatic patients were tested for CF. The patients described illustrate the difficulty in making blanket phenotype predictions based on genotype information in this disorder.

Excluding patients with I148T and R117H without 5T, in our series of 335,204 patients, only 4 patients were discovered to have $2 \mathrm{CF}$ mutations who did not previously have the diagnosis of CF, yielding a "false positive" rate of $0.0012 \%$ for $2 \mathrm{CF}$ mutations. This means that when a prenatal diagnosis discovers two ACMG mutations in a fetus, genetic counseling can be performed with confidence. Whether counseling recommendations should be altered for patients with $2789+5 \mathrm{G} \rightarrow \mathrm{A}$ will require further data.

\section{Prenatal diagnosis for CF}

We received 445 prenatal samples for CF mutation analysis. Table 4 contains a compilation of indications for testing and resultant diagnoses. Of 90 fetuses at a 1:4 risk for CF (two carrier parents), 17 (19\%) affected fetuses were identified. In all, 5 prenatal diagnoses were performed identifying one parent as heterozygous for I148T. One mother was a compound heterozygote for delta F508 and R117H (without 5T), the father was heterozygous for I148T, and the fetal genotype was delta F508/I148T. This couple received counseling regarding the significance of I148T and elected to continue the pregnancy. We were unable to obtain follow up. Fortunately, none of the other 4 couples in which one parent is heterozygous for 
Table 4

Summary of prenatal CF tests

\begin{tabular}{|c|c|c|c|c|}
\hline Indication for prenatal & No. of procedures & No. affected & No. heterozygotes & No. homozygous wild type \\
\hline Both parents CF carriers & 90 & 17 & 45 & 28 \\
\hline Echogenic bowel & 100 & 1 & 5 & 94 \\
\hline Abnormal sonogram (not echogenic bowel) & 5 & 0 & 1 & 4 \\
\hline Family history of CF (Parents not tested) & 20 & 0 & 3 & 17 \\
\hline $\begin{array}{l}\text { Population screening (Prenatal performed } \\
\text { for other indications) }\end{array}$ & 88 & 0 & 4 & 84 \\
\hline One parent carrier & 57 & 0 & $31^{a}$ & 26 \\
\hline One parent carrier other parent $5 \mathrm{~T}$ & 33 & 0 & 19 & 14 \\
\hline One or both parents $5 \mathrm{~T}$ & 32 & 0 & 0 & 0 \\
\hline Miscellaneous & 3 & 0 & 1 & 2 \\
\hline Indication unavailable & 17 & 0 & 1 & 16 \\
\hline
\end{tabular}

${ }^{a} 1$ patient was compound heterozygous for R117H/delta F 508 and negative for 5T.

I148T and the other for delta F508 had potentially affected genotypes and no pregnancy losses occurred.

In our series, we identified 10,319 CF carriers. With a carrier frequency of 1:33 (see earlier), we would estimate that 312 couples $(10,319 / 33)$ to be at $1: 4$ risk although there is no way for us to validate this estimate. However, we received only 90 prenatal diagnostic samples during the same period of time from couples at 1:4 risk. We feel that the most likely explanation for this phenomenon is that we did not receive the prenatal specimens from many prenatal diagnoses performed on couples identified through our testing program. Our experience suggests that many couples are referred to physicians other than the primary obstetrician for genetic counseling and the prenatal procedure. These specialty physicians may choose to send prenatal specimens to a different referral laboratory. Therefore it would be unwise to make any estimates of cost per identified affected fetus based on this data set. Such calculations can only come from clinics who perform all their own screening and prenatal procedures. In addition, in 90 prenatal diagnoses for parents at 1:4 risk, we observed only 18 affected fetuses rather than the expected number of 22. This is most likely due to the low number of cases and we would hypothesize this figure to normalize with a larger data set.

Echogenic bowel was the indication for prenatal diagnosis in 100 cases. In only a single instance were both parents tested and found to be CF carriers before the amniocentesis. That fetus was the only affected fetus in our series of 100 cases. In the remaining cases, amniocentesis was performed simultaneously with carrier testing, or carrier testing was not performed at all. None of these 99 fetuses were affected with CF and only 5 were $\mathrm{CF}$ carriers. The 5\% CF carrier frequency in fetuses with echogenic bowel is not dramatically higher than the 3\% general carrier rate in the population. Our data support the estimates of Hodge et al. ${ }^{15}$ of a $1 \%$ risk of CF in a fetus with echogenic bowel.

The remainder of the prenatal CF tests were performed for other indications (see Table 4). Of note is that no affected fetuses were detected in any of these circumstances, emphasizing the importance of performing carrier testing on parents either before pregnancy or early in gestation so that unnecessary amniocentesis can be avoided.

\section{Clinical significance of $\mathbf{5 T}$}

The ACMG statement recommends that the $5 \mathrm{~T}$ allele be analyzed as a reflex in the presence of the $\mathrm{R} 117 \mathrm{H}$, a usually mild $\mathrm{CF}$ mutation. The presence of a $5 \mathrm{~T}$ allele causes aberrant splicing and reduces the amount of functional CFTR mRNA from the gene containing it. ${ }^{16-18}$ The ACMG recommendation is based on 2 factors: an effort to screen only for patients at risk for offspring with classic CF and the fact the R117H mutation, when on a chromosome that does not contain a $5 \mathrm{~T}$ allele, usually does not cause classic CF in combination with a classic CF mutation. Compound heterozygous males for $\mathrm{R} 117 \mathrm{H}$ and a classical CF mutation are often infertile due to congenital bilateral absence of the vas deferens (CBAVD). This combination can also cause atypical phenotypes. However, when an allele contains $\mathrm{R} 117 \mathrm{H}$ and a $5 \mathrm{~T}$, this allele can cause classic CF when inherited with a classic CF mutation. Our previously published data revealed a gene frequency of 0.046 for the $5 \mathrm{~T}$ allele and a carrier frequency of $9.2 \%$ in 20,103 patients. ${ }^{12}$

The most common CF mutation, delta F508, occurs almost exclusively on chromosomes containing the $9 \mathrm{~T}$ variant. Patients who are carriers for delta F508 and have the IVS-8 genotype 5T/9T can be assumed to have the 5T in trans. Patients with this genotype present a unique opportunity to investigate the phenotype of patients who inherit a CF mutation from one parent and 5T from the other. In our series, there were 219 such patients for whom we were able to obtain clinical information. There were 184 females of whom 177 had no symptoms attributable to CF, six patients who have asthma, and one who has had sinus surgery. The incidence of asthma of 6 per 184 or 32 per 1000 is actually below the population frequency in the US of 96.6/1000 reported by Center for Disease Control. ${ }^{19}$ Noone et al. ${ }^{19,20}$ described two female patients who pre- 
sented with lung disease suggestive of $\mathrm{CF}$, one of whom was homozygous for $5 \mathrm{~T}$ alone with normal sequence analysis of CFTR, and another who was a compound heterozygote for delta F508 and 5T. It is possible that these 2 patients have CF not associated with CFTR mutations ${ }^{21}$ or that other sequence variations such as the intron $8 \mathrm{TG}$ repeat polymorphism influence the penetrance of the 5T genotype. ${ }^{22}$

There were 35 males compound heterozygous for delta F508 and 5T. Unlike the females with the same genotype (see earlier), more than half these patients experienced symptoms attributable to CF. Twelve (34\%) have CBAVD, 3 have pulmonary symptoms, and of the 20 remaining patients, only 10 had fathered children and none of the 20 had pulmonary disease. Although this series clearly suffers from ascertainment bias because most men were probably tested due to their symptoms, the data do reinforce the observations that many men with CBAVD have a genotype of one CF mutation and a $5 \mathrm{~T}$ in trans. ${ }^{23-25}$ We were unable to determine how many of these men were tested because of fertility problems versus population-based carrier screening. Chillon et al. ${ }^{23}$ described 3 adult males with CBAVD and lung disease who were compound heterozygotes for delta F508 and 5T.

We also investigated the clinical effect of homozygosity for 5T. We randomly selected 84 of the 219 patients with that genotype and obtained clinical information. Of 75 women, 4 had mild respiratory symptoms. Of the 9 men, 1 has CBAVD and 1 is oligospermic but this series again suffers from ascertainment bias. Although it is impossible to say with certainty that homozygosity for the $5 \mathrm{~T}$ allele is completely benign, any potential risk appears to be limited to infertility in males.

\section{Conclusion}

This article summarizes our experience with populationbased carrier screening using the ACMG recommended panel. The single genotype/phenotype error regarding I148T was recognized quickly and interpretative reporting comments adjusted accordingly. The difficulties encountered secondary to the reporting of the $5 \mathrm{~T}$ variant in population screening are being publicized and should be minimized quickly. It should be noted that these difficulties were secondary to lack of complete compliance with the ACMG guidelines and not a lack of thoroughness in the guidelines. As we gain more experience in population-based CF carrier detection, progressively more accurate genetic counseling can be performed adding to the effectiveness of the program. In order to investigate the cost effectiveness of CF population-based carrier screening data must be generated from settings performing both carrier screening and prenatal diagnosis.

\section{References}

1. Grody WW, Cutting GR, Klinger KW, Richards CS, Watson M, Desnick RJ. Laboratory standards and guidelines for population-based cystic fibrosis carrier screening. Genet Med 2001;3:149-154.
2. American College of Obstetrics and Gynecology and American College of Medical Genetics, Preconception and prenatal carrier screening for Cystic Fibrosis, clinical and laboratory guidelines, 2001. American College of Obstetrics and Gynecology publication. Washington, DC; October 2001.

3. Behrman RE. Cystic fibrosis. In: Nelson Textbook of Pediatrics, 14th ed, Philadelphia: WB Saunders Co., 1992:1106-1116.

4. Welsh MJ, Ramsey BW, Accurso F, Cutting G. Cystic Fibrosis. In: The Metabolic and Molecular Basis of Inherited Disease. Scriver CR, Beaudet AL, Sly WS, Valle D, Childs, B, Kinzler KW et al, editors, New York: McGraw Hill, 2001:5121-5188.

5. Cystic Fibrosis Foundation. About Cystic Fibrosis. Available at: http://www.cff.org. Accessed June 20, 2003.

6. Palomaki GE, Haddow JE, Bradley LA, FitzSimmons SC. Updated assessment of cystic fibrosis mutation frequencies in non-Hispanic Caucasians. Genet Med 2002; 4:90-94.

7. Rommens JM, Ianuzzi MC, Kerem B-S, Drumm ML, Melmer G, Dean M et al. Identification of the cystic fibrosis gene: chromosome walking and jumping. Science 1989;245:1059-1065.

8. Riordan JR, Rommens JM, Kerem B-S, Alon N, Rozmahel R, Grzelczak Z et al. Identification of the cystic fibrosis gene: cloning and characterization of complimentary DNA. Science 1989;245:1066-1073.

9. Kerem, B-S, Rommens JM, Buchanon JA, Markiewicz D, Cox TK, Chakravarti A et al. Identification of the cystic fibrosis gene: genetic analysis. Science 1989;245:10731080 .

10. Hospital for Sick Children, Toronto. Cystic Fibrosis Mutation Database. Available at: http://www.genet.sickkids.on.ca/cftr. Accessed June 20, 2003.

11. Watson MS, Desnick RJ, Grody W, Mennuti MT, Popovich BW, Richards S. Cystic Fibrosis carrier screening: Issues in implementation. Genet Med 2002;4:407-409.

12. Strom CM, Huang D, Buller A, Redman J, Crossley B, Anderson B et al. Cystic fibrosis screening using the College Panel: Platform comparison and lessons learned from the first 20,000 samples. Genet Med 2002;4:289-296.

13. Rohlfs EM, Zhou Z, Sugarman EA, Heim RA, Pace RG, Knowles MR et al. The I148T allele occurs on multiple haplotypes: A complex allele is associated with cystic fibrosis. Genet Med 2002:319-323.

14. McKone EF, Emerson SS, Edwards KL, Aitken ML. Effect of genotype on phenotype and mortality in cystic fibrosis: a retrospective cohort study. Lancet 2003;361:16711676.

15. Hodge SE, Lebo R, Yesley AR, Cheney SM, Angle H, Milunsky J. Calculating posterior risk with echogenic bowel and one characterized cystic fibrosis mutation. Am J Med Genet 1999;82:329-335.

16. Rave-Harel N, Kerem E, Nissim-Rafinia M, Madjar I, Goshen R, Augarten A et al. The molecular basis of partial penetrance of splicing mutations in cystic fibrosis. Am J Hum Genet 1997;60:87-94.

17. Chu CS, Trapnell BC, Curristan S, Cutting GR, Crystal RG. Genetic basis of variable exon 9 skipping in cystic fibrosis transmembrane regulator mRNA. Nat Genet 1993; 3:151-156.

18. Dork T, Fislage R, Neumann T, Wulf B, Tummler B. Exon 9 of the CFTR gene: splice site haplotypes and cystic fibrosis mutations. Hum Genet 1994;93:67-73.

19. Center for Disease Control. Surveillance for Asthma: United States, 1980-1999. Available at: http://cisat.isciii.es/mmwr/preview/mmwrhtml/ss5101al.htm. Accessed June 20, 2003.

20. Noone PG, Knowles MR. 'CFTR-opathies': disease phenotypes associated with cystic fibrosis transmembrane regulator gene mutations. Resp Res 2001;2:328-332.

21. Noone PG, Pue CA, Zhou Z, Freidman KJ, Wakeling EL, Ganeshananthan M et al. Lung disease associated with the IVS8 5 T allele of the CFTR gene. A J Resp Crit Care Med 2000;162:1919-1924.

22. Groman JD, Hefferon TW, Casals T, Bassas L, Estivill X, Des Georges M et al. Variation in a repeat sequence determines whether a common variant of the Cystic Fibrosis Transmembrane Conductance Regulator gene is pathogenic or benign. Am J Hum Genet 2004;74:176-179.

23. Groman J, Meyer ME, Wilmott RW, Zeitlin PL, Cutting, GR. Variant cystic fibrosis phenotypes in the absence of CFTR mutations. N Engl J Med 2002;347:401-407.

24. Chillon M, Casals T, Bassas L, Lissens W, Silber S, Romey MC et al. Estivill X. Mutations in the cystic fibrosis gene in patients with congenital absence of the vas deferens. N Engl J Med 1995;332:1474-80.

25. Costes B, Giroden E, Ghanem N, Fiori E, Jardin A, Souffir JC et al. Frequent occurrence of the CFTR intron 8 (TG)n 5T allele in men with congenital absence of the vas deferens. Eur J Hum Genet 1995;3:285-93. 